\title{
PENGARUH VARIASI TEMPERATUR SINTERING TERHADAP UMUR TANUR PADA INDUSTRI KERAJINAN GONG DI GIANYAR
}

\author{
Gede Widayana ${ }^{1}$, I Nyoman Pasek Nugraha ${ }^{2}$,Nyoman Arya Wigraha ${ }^{3}$ \\ ${ }^{123}$ Jurusan Pendidikan Teknik Mesin, Fakultas Teknik dan Kejuruan \\ Universitas Pendidikan Ganesha Singaraja \\ Bali Indonesia \\ e-mail : gedewidayana@gmail.com
}

\begin{abstract}
Abstrak
Keramik merupakan salah satu kerajinan tradisional yang telah ada sejak berabad-abad lalu. Salah satu jenisnya adalah tanur krus grafit yang banyak digunakan pada industri-industri pengecoran terutama untuk mencairkan logam. Dalam penggunaannya tanur krus grafit ini mengalami keretakan setelah pemakaian 5 atau 6 kali. Hal ini disebabkan karena material yang dipakai tidak memenuhi standar dan proses yang dilakukan masih belum sempurna.Penelitian ini dilakukan dengan merubah komposisi material yaitu terdiri dari fraksi halus $30 \%$, fraksi kasar $40 \%$ dan clay $30 \%$ dan memakai proses sintering pada temperature $1000^{\circ} \mathrm{C}$ dan $1100^{\circ} \mathrm{C}$ untuk meningkatkan kekuatan tanur sehingga diharapkan dapat memperpanjang umur tanur. Hasil penelitian menunjukan bahwa pada temperature sintering $1100^{\circ} \mathrm{C}$ mendapatkan berat jenis, nilai porositas dan nilai abrasi yang lebih baik pada tanur sehingga umur tanur dapat diperpanjang hingga lebih dari 10 kali pakai.
\end{abstract}

Kata kunci : keramik, tanur krus grafit, sintering.

\begin{abstract}
Ceramics is one of the traditional craft that has been around since centuries ago. One type is a graphite crucible furnaces are widely used in foundry industries especially for the metal melt. In use graphite crucible furnace is developing cracks after use 5 or 6 times. This is because of the materials used does not meet the standards and the process is still not complete. The study has been done by changing the composition of the material consists of fine fraction $30 \%, 40 \%$ coarse fraction and $30 \%$ clay and wear sintering process at temperatures of $1000^{\circ} \mathrm{C}$ and $1100^{\circ} \mathrm{C}$ furnace to increase the strength of which is expected to extend the life of the furnace. The results showed that the sintering temperature of $1100^{\circ} \mathrm{C}$ to get the density, porosity values and abrasion better value in the furnace so that the age of the furnace can be extended to more than 10 times the life.
\end{abstract}

Keywords: ceramic, graphite crucible furnaces, sintering. 


\section{PENDAHULUAN}

Sejak dahulu nenek moyang kita telah mewariskan kekayaan berbentuk seni tradisional, baik yang primitif maupun klasik. Banyak karya seni yang mengagumkan telah mereka ciptakan diantaranya seni tari, seni ukir, seni batik, seni anyaman dan seni keramik, termasuk perabotan rumah tangga, keperluan upacara serta hiasan dengan berbagai bentuk dan variasinya. Hasil karyanya tersebut telah mampu menjadi tradisi bagi generasi selanjutnya dalam kurun waktu yang tidak terbatas sampai dewasa. Sebagai generasi penerus kita dituntut untuk melestarikan dan mengembangkan seni tradisional tersebut sesuai dengan kenyataan dan tantangan jaman sekarang ini selaras dengan perkembangan dan kebutuhan masyarakat. Keramik yang merupakan salah satu kerajinan tradisional telah ada sejak berabad-abad yang lalu. Di Eropa keramik diperkenalkan setelah kemenangan Islam di Afrika Utara dan Spanyol. Sejak itu keahlian membuat keramik mulai berkembang di daerah tersebut dan meluas ke negeri Eropa dan Asia melalui perdagangan. Keramik sebagai salah satu bagian dari kehidupan masyarakat berkembang sesuai dengan kemajuan teknologi dan ilmu. Dalam bidang teknik terlihat penggunaannya dibidang ruang angkasa, kedokteran dan peralatan teknik canggih. Sedang dalam masyarakat umumnya tampil dalam bentuk keramik fungsi, keramik seni dan keramik kerajinan.

Tanur krus grafit merupakan salah satu jenis keramik yang banyak digunakan pada industri-industri pengecoran terutama untuk mencairkan paduan tembaga .
Seperti di Kerajinan Gong di Blahbatuh Gianyar, tanur krus grafit disana digunakan untuk membuat barang-barang kerajinan Gong. Namun dalam prakteknya tanur krus grafit ini sering mengalami retak setelah pemakaian $5-6$ kali pakai. Sehingga tentunya krus grafit tersebut harus diganti.Jika dilihat dari sudut ekonomi jelas penggantian tersebut akan memakan biaya dan waktu yang tidak sedikit sehingga kelancaran produksi akan terganggu.Perlu dijelaskan sedikit bahwa industri Kerajinan Gong tempat melakukan survey merupakan industri kecil dengan modal yang tidak terlalu besar dan tanur krus grafit yang dipakai adalah dibuat sendiri dengan bahan baku yang mereka beli diluar, merupakan bekas dari tanur yang sudah tidak dipakai lagi.

Tanur merupakan salah satu jenis bahan keramik yang mengalami proses pembakaran dimana proses tersebut sangat menentukan sifat-sifat bahan nantinya. Dimana pada proses pembakaran/perlakuan panas ini terjadi peristiwa kimia seperti pengeringan, peruraian bahan, penguapan air kristal, oksidasi bahan logam dan lainnya. Terjadinya peristiwa kimia ini dinamakan reaksi kimia yang akan diikuti dengan perubahan fisis yaitu sintering. Sintering adalah proses penggabungan partikelpartikel serbuk melalui peristiwa difusi pada suhu yang tinggi.Dengan proses sintering ini maka pori-pori antara partikel bahan akan dapat dihilangkan sehingga terjadi penyusutan komponen dan akan diikuti dengan pertumbuhan grain serta meningkatkan ikatan antar partikel, sehingga nantinya akan dihasilkan bahan yang lebih mampat dan tentunya akan lebih kuat. Pada 
penelitian Charusporn Mongkolkachit dkk (2010), "Effect of Sintering Temperature on Porous Structure of Freeze Cast Alumina", menyimpulkan bahwa dengan proses sintering porositas bahan oksid aluminium semakin meningkat, pertumbuhan butir oksid aluminium juga semakin meningkat dengan meningkatnya temperatue sintering dati $1400^{\circ} \mathrm{C}$ sampai $1600^{\circ} \mathrm{C}$. Pada penelitian Mostafa Roosta,dkk (2011), "The Effect of Using Nano $\mathrm{ZrO}_{2}$ on the Properties of $W$-ZrC Composite Fabricated through Reaction Sintering", menunjukkan bahwa terjadi peningkatan pada kepadatan, kekerasan, modulus elastisitas dan kuat lendut dari material W-ZrC setelah dilakukan proses sintering diatas temperature $900^{\circ} \mathrm{C}$. Pada penelitian Ramlan dan Akhmad A Bama (Juli 2011), " Pengaruh Suhu dan Waktu Sintering terhadap Sifat Bahan Porselin untuk Bahan Elektrolit Padat (Komponen Elektronika)." Mendapatkan kesimpulan bahwa kenaikkan suhu sintering akan meningkatkan densitas bahan, kuat patah, kuat tembus dan bahan porselin dengan suhu sinter $1300^{\circ} \mathrm{C}$ dapat diaplikasikan sebagai insulator listrik tegangan menengah.

Subowo (2003) dalam penelitiannya berjudul, "Pengaruh Temperatur Sintering Terhadap Sifat Mekanik Keramik Insulator Listrik.", menyimpulkan bahwa porositas keramik semakin kecil dengan meningkatnya temperature sintering dan ikatan antar permukaan yang terjadi sempurna pada temperature sintering $1200^{\circ} \mathrm{C}$. Dari referensi-referensi diatas penulis mengambil kesimpulan bahwa proses Sintering sangat bagus dilakukan untuk meningkatkan kekuatan bahan keramik , baik dilihat dari porositas, densitas, kekerasan, kuat lendut, kuat patah, dan lain sebagainya. Maka dari itu pada penelitian kami ini akan memakai proses sintering untuk menambah kekuatan dari tanur yang kami teliti ini. Disamping itu juga dengan memperbaiki komposisi material dari tanur dengan menambahkan fraksi kasar akan tentunya menambah kekuatan bahan tanur tersebut.

Berdasarkan latar belakang dan identifikasi masalah diatas, maka dapat dirumuskan permasalahannya adalah bagaimana pengaruh temperatur Sintering terhadap properties bahan keramik? Tujuan dilakukan penelitian ini adalah untuk memperbaiki komposisi dari tanur krus grafit dan mendapatkan temperatur sintering yang baik sehingga diharapkan dapat memperpanjang umur dari tanur tersebut. Adapun pemecahan masalah pada penelitian ini adalah dengan melakukan perbaikan mengenai cara pembuatan dari tanur krus grafit. Dalam penelitian ini dirubah komposisi material dengan menambah fraksi kasar (lolos ayakan $3 \mathrm{~mm}$ ) dan mengganti tanah liat dengan clay ngandang. Disamping itu juga dilakukan proses Sintering pada tanur dengan memakai 2 variasi temperatur sintering untuk mendapatkan temperature sintering yang paling baik agar dapat memperpanjang umur tanur. Dengan dilakukannya penelitian ini manfaat yang bisa didapatkan adalah membantu dalam pembuatan tanur krus grafit sehingga didapatkan umur tanur yang lebih lama untuk menunjang kelancaran dan meningkatkan proses produksi dan keuntungan yang didapat di industri kecil pengecoran logam kuningan pembuatan Gong di Blahbatuh Gianyar. 
Luaran yang diharapkan dari penelitian ini diantaranya hasil penelitian yang dihasilkan dapat digunakan untuk meningkatkan dan memperlancar proses produksi kerajinan Gong di Blahbatuh Gianyar, Metode proses sintering yang dilakukan dapat dipakai untuk proses pengecoran yang lainnya selain tembaga sehingga akan meningkatkan pengetahuan pengerajin tentang pengecoran yang baik.

\section{METODE EKSPERIMEN}

Kerajinan Gong di Blahbatuh ini dalam pembuatan tanur krus grafit sangat sederhana. Komposisi material dan temperatur bakar (sintering) hanya berdasarkan kira-kira saja, sehingga untuk mendapatkan umur tanur yang maksimal perlu suatu komposisi material dan temperatur bakar yang tepat dan diharapkan nilai abrasinya kecil.

Pada penelitian ini metode yang dipakai adalah metode penelitian pengembangan (Research and development) dimana data diambil dari tanur yang dibuat dengan komposisi material yang telah dirubah. Ada 2 buah sampel tanur yang dibuat untuk dilakukan proses perlakukan yang berbeda. Tanur yang pertama dilakukan proses sintering pada suhu $1000 \mathrm{C}$ dan tanur yang kedua dilakukan proses sintering pada suhu 1100 C. Setelah dilakukan proses sintering pada masingmasing suhu tersebut maka dilakukan waktu penahanan sintering selama 1 jam dan setelah itu burner dimatikan. Proses selanjutnya adalah proses pendinginan yang dilakukan secara lambat tanpa bantuan apapun. Setelah proses pendinginan selesai maka dilakukan uji material pada masingmasing tanur tersebut dengan mengambil sampel bagian tanur. Pengujian yang dilakukan adalah pengujian berat jenis, porositas dan nilai abrasi. Pengujian yang dilakukan untuk mendapatkan nilai dari ketiga proses uji tersebut dari komposisi material baru penyusun tanur. Dari pengujian ini kemudian dilakukan analisa data untuk mendapatkan hasil. Analisa data yang dilakukan untuk mendapatkan berat jenis komposisi material penyusun tanur dengan membandingkan besarnya nilai berat jenis pada perbedaan perlakuan proses sintering.

Begitu juga dengan analisa data untuk nilai porositas dan abrasi.

Alur proses mulai dari bahan baku, pencampuran sampai pada pengujian , hasil pengujian, analisa dan kesimpulan terlihat pada plot bagan dibawah ini. 


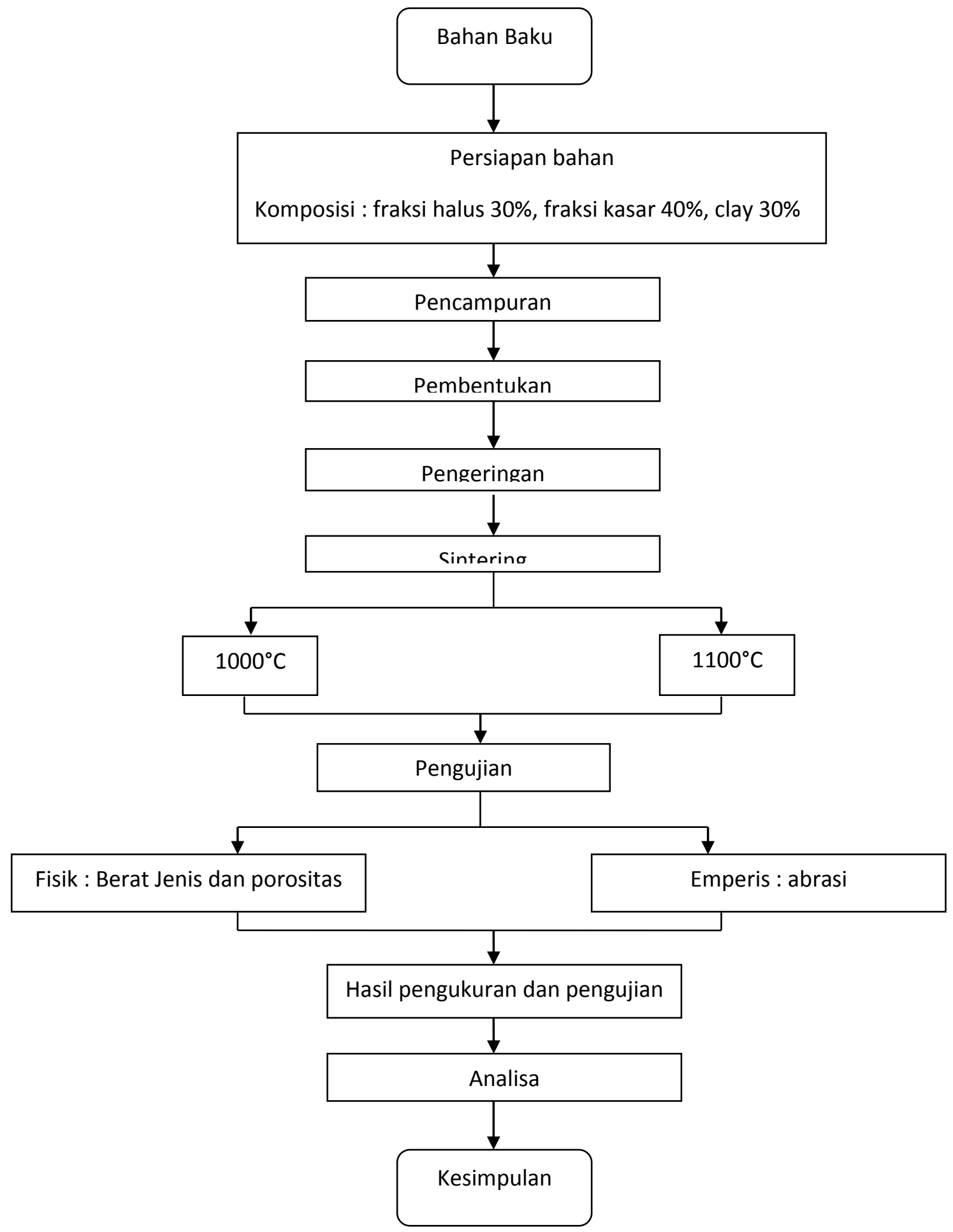

Gambar 1. Alur proses pengujian tanur 


\section{Tahapan Proses Pembuatan Tanur Krus Grafit \\ Persiapan bahan}

Bahan baku pembuatan tanur krus grafit adalah campuran tanah liat (clay) dengan fraksi halus $(0,5 \mathrm{~mm})$ dan fraksi kasar $(3 \mathrm{~mm})$. Ketiga bahan tersebut dicampur pada proses pencampuran. Perbandingan komposisi antara clay, fraksi halus dan fraksi kasar adalah seperti tabel di bawah.

Untuk mengetahui temperatur bakar (sintering) yang paling baik maka dibuat 2 macam variasi temperatur bakar.

Tabel 1 : Komposisi material yang di sintering

\begin{tabular}{lll}
\hline Komposisi & \multicolumn{2}{c}{ Sintering } \\
& $1000^{\circ} \mathrm{C}$ & $1100^{\circ} \mathrm{C}$ \\
\hline Fraksi halus & $30 \%$ & $30 \%$ \\
$(0,5 \mathrm{~mm})$ & & \\
Fraksi kasar $(3 \mathrm{~mm})$ & $40 \%$ & $40 \%$ \\
Clay & $30 \%$ & $30 \%$ \\
\hline
\end{tabular}

\section{Pencampuran}

Pada tahap ini bahan yang telah disiapkan dicampur secara merata dengan ditambahkan air sebesar 5\% (1250 ml). Setelah tercampur semuanya adonan tersebut siap untuk dibentuk.

\section{Pembentuan}

Pembentukan tanur krus grafit ini dilakukan pada cetakan yang sebelumnya dilapisi dengan plastik agar adonan tidak lengket pada cetakan. Dalam proses pembentukan ini juga dilakukan penekanan terhadap material untuk mendapatkan porositas yang sekecil-kecilnya.

\section{Pengeringan}

Tujuan utama dari proses pengeringan ini adalah untuk mengurangi kadar air dalam pori-pori partikel. Proses ini penting setelah proses pembentukan. Selama proses pengeringan terjadi perpindahan massa dan panas yang terjadi secara serentak. Perpindahan massa disebabkan perbedaan kadar air yang bergerak dari tempat basah ke ruang yang lebih kering dan juga berpindah dari bagian dalam bahan ke permukaan bidang penguapan, untuk selanjutnya menguap. Sedangkan perpindahan panas terjadi karena perbedaan suhu antara bagian dalam dan permukaan material. Untuk mendapatkan kondisi pengeringan yang baik (perpindahan massa dan panas) maka suhu penguapan harus baik. Penguapan yang cepat akan mengakibatkan adanya retak-retak pada tanur. Hal ini disebabkan karena terjadinya perbedaan kadar air pada bagian permukaan dan bagian dalam tanur. Untuk itu proses pengeringan dilakukan 2-3 hari.

\section{Sintering}

Dalam proses sintering terjadi perubahan material sbb :

- Berkurangnya luas permukaan

- Kekuatan meningkat

- Kerapatan meningkat

Untuk proses sintering dilakukan pada Shutle Kiln yaitu dapur pembakaran yang berukuran $0,5 \mathrm{~m} \times 0,5 \mathrm{~m}$ dan thermokopel yang gunanya untuk mengukur suhu pembakaran.

Temperatur sintering yang digunakan adalah temperature $1000^{\circ} \mathrm{C}$ dan $1100^{\circ} \mathrm{C}$. Setelah tercapai temperature maksimum sintering kemudian dilakukan penahanan selama 1 jam dan setelah itu 
burner dimatikan dan dilakukan pendinginan secara lambat.

Proses pemanasan (sintering) yang dilakukan menyebabkan perubahan pada struktur butiran.Dimana akan mengakibatkan ikatan pada butiranbutiran material . Ikatan ini yang mengisi ruang kosong material sehingga kepadatannya akan semakin baik.

\section{Pengujian}

Pengujian yang dilakukan terhadap tanur adalah pengujian berat jenis, porositas dan abrasi.

a. Berat Jenis

Untuk mendapatkan berat jenis dari tanur, tanur ditimbang berat basah, berat kering dan berat dalam air nya.

\section{Dimana :}

$$
B J=\frac{B K}{B B-B D A}
$$

$\left(\mathrm{kg} / \mathrm{mm}^{3}\right)$

BJ = Berat jenis

$$
\begin{aligned}
& \mathrm{BK}=\text { Berat kering }(\mathrm{kg}) \\
& \mathrm{BB}=\text { Berat basah }\left(\mathrm{mm}^{3}\right) \\
& \mathrm{BDA}=\text { Berat dalam air }
\end{aligned}
$$

$\left(\mathrm{mm}^{3}\right)$

b. Porositas

Nilai porositas tanur dapat dicari dengan rumus seperti dibawah ini.

$$
N P=\frac{B B-B K}{B B-B D A} \times 100 \%
$$

(\%)

Dimana : NP $=$ Nilai Porositas

c. Abrasi

Pada pengujian abrasi ini kita asumsikan material secara makrostruktur adalah sama. Uji abrasi ini menggambarkan ketahanan tanur pada kondisi pemakaian. Untuk uji abrasi pada tanur dipakai mesin polisher, kertas gosok dan jig yang berguna untuk mencekam material agar dalam kondisi yang tetap selama putaran mesin.

\section{ANALISA DATA HASIL PEGUJIAN Berat Jenis}

\begin{tabular}{|c|c|c|c|c|}
\hline $\begin{array}{l}\text { Temperat } \\
\text { ur } \\
\text { Sintering } \\
\left({ }^{\circ} \mathrm{C}\right)\end{array}$ & $\begin{array}{l}\text { Berat } \\
\text { kerin } \\
g \\
\text { tanur }\end{array}$ & $\begin{array}{l}\text { Berat } \\
\text { basa } \\
\mathrm{h} \\
\text { tanur }\end{array}$ & $\begin{array}{l}\text { Berat } \\
\text { dala } \\
\text { m air } \\
\text { tanur }\end{array}$ & $\begin{array}{l}\text { Bera } \\
t \\
\text { Jeni } \\
s\end{array}$ \\
\hline 1000 & 4,5 & 4,91 & 2,45 & $\begin{array}{c}1,82 \\
9\end{array}$ \\
\hline 1100 & 4,45 & 4,7 & 2,34 & $\begin{array}{c}1,88 \\
5\end{array}$ \\
\hline
\end{tabular}

Hasil Pegujian tanur setelah dilakukan proses sintering dapat dilihat pada tabel 2 dibawah ini

Tabel 2. Hasil pengujian Berat jenis

Terlihat bahwa berat jenis tanur pada temperature sintering $1100^{\circ} \mathrm{C}$ lebih besar dibanding pada temperature sintering $1000^{\circ} \mathrm{C}$. Ini disebabkan karena dengan tingginya temperature sintering maka peleburan material akan lebih cepat dan waktu terjadinya reaksi pengikatan/perekatan antara partikelpartikel akan berlangsung lebih lama, yang mana fraksi halus material akan melebur mengikat material fraksi kasar. Hal ini yang mengakibatkan berat jenisnya lebih besar.

\section{Porositas}

Nilai porositas yang didapat dari hasil pengujian tanur adalah seperti pada tabel 3. Untuk temperature sintering $1100^{\circ} \mathrm{C}$, nilai porositasnya lebih kecil dibanding temperature sintering $1000^{\circ} \mathrm{C}$ . Pada pembakaran/sintering $1100^{\circ} \mathrm{C}$ proses perekatan dan pemadatan antar butir terjadi lebih sempurna dimana ruang antar butir menjadi rapat dan 
menghambat masuknya gas-gas seperti gas $\mathrm{O}_{2}, \mathrm{CO}$,dsb yang dapat merusak tanur pada waktu pengoperasiannya nanti.

Tabel 3. Hasil pengujian Porositas

\begin{tabular}{ll}
\hline Temperatur & Nilai \\
Sintering $\left({ }^{\circ} \mathrm{C}\right)$ & Porositas
\end{tabular}

\begin{tabular}{ll}
\hline 1000 & 16,67 \\
1100 & 10,59 \\
\hline
\end{tabular}

Tabel 4. Hasil pengujian abrasi,sintering

\begin{tabular}{clll}
\multicolumn{2}{c}{$1000^{\circ} \mathrm{C}$} & & \\
\cline { 1 - 3 } Potongan & \multicolumn{2}{c}{ Berat Potongan } & Nilai \\
\cline { 2 - 3 } & $\begin{array}{c}\text { Sebelum } \\
\text { Abrasi }\end{array}$ & $\begin{array}{l}\text { Setelah } \\
\text { Abrasi }\end{array}$ & \\
\hline 1 & 111,334 & 111,325 & 0,009 \\
2 & 112,438 & 112,431 & 0,007 \\
3 & 111,546 & 111,542 & 0,004 \\
& \multicolumn{2}{c}{ Rata-rata } & 0,0067
\end{tabular}

Tabel 5. Hasil pengujian abrasi $1100^{\circ} \mathrm{C}$

\begin{tabular}{cccc}
\hline Potongan & \multicolumn{2}{c}{ Berat Potongan } & Nilai \\
& $\begin{array}{c}\text { Sebelum } \\
\text { Abrasi }\end{array}$ & $\begin{array}{l}\text { Setelah } \\
\text { Abrasi }\end{array}$ & Abrasi \\
\hline 1 & 111,339 & 111,333 & 0,006 \\
2 & 112,433 & 112,428 & 0,005 \\
3 & 111,543 & 111,541 & 0,002 \\
& Rata-rata & 0.0043
\end{tabular}

\section{Abrasi}

Hasil pengujian abrasi untuk 1 tanur dengan 3 macam contoh potongan adalah seperti pada tabel 4 dan 5 .

Nilai abrasi pada temperature sintering $1100^{\circ} \mathrm{C}$ lebih kecil dibanding temperatur $1000^{\circ} \mathrm{C}$. Ini menandakan kepadatan dan kerapatan material yang lebih baik karena sempurnanya proses perekatan partikel-partikel material yang terjadi pada temperature tersebut.

\section{HASIL DAN PEMBAHASAN}

Nilai Berat Jenis yang terbesar terjadi pada temperature sintering $1100^{\circ} \mathrm{C}$, dimana nilai yang terbesar ini menunjukkan hasil baik karena berat jenis yang besar menandakan proses perekatan partikel yang sempurna, seperti terlihat pada Gambar 1. Pada Gambar 2. nilai porositas yang paling kecil yang baik. Ini menandakan proses pemadatan terjadi lebih sempurna. Nilai abrasi yang terkecil adalah yang paling baik karena enandakan semakn kuat dan padatnya partikel material yang merekat.Seperti terlihat pda Gambar 3. 


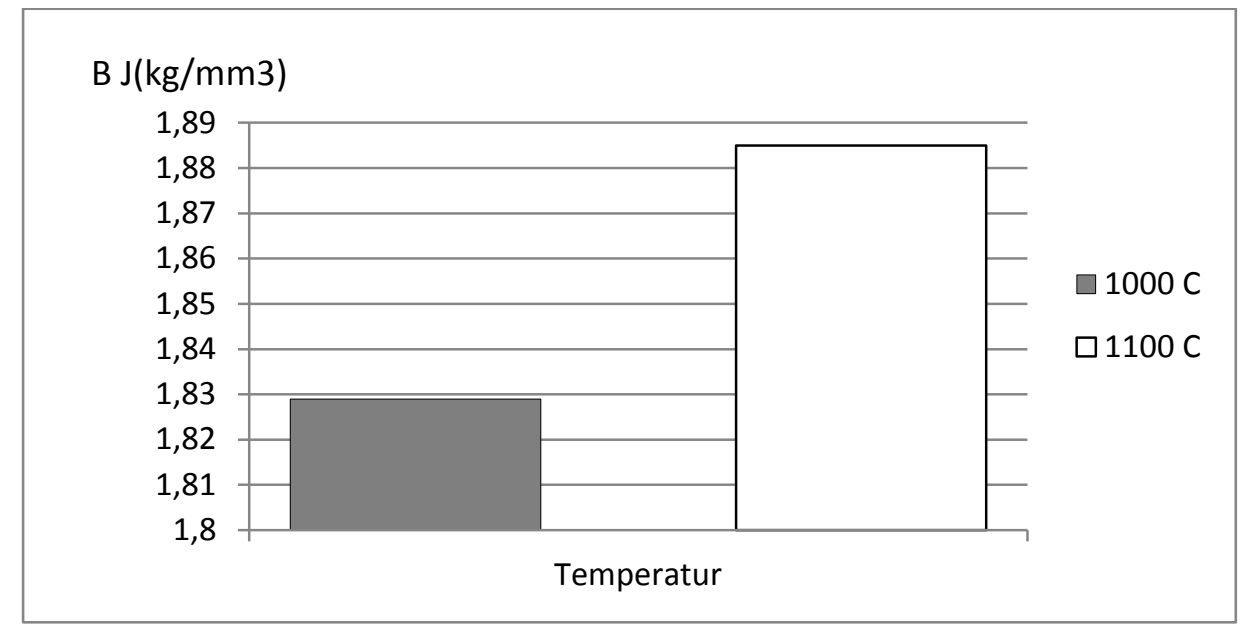

Gambar 2. Plot Temperatur Sintering dan besarnya Berat Jenis $\left(\mathrm{kg} / \mathrm{mm}^{3}\right)$

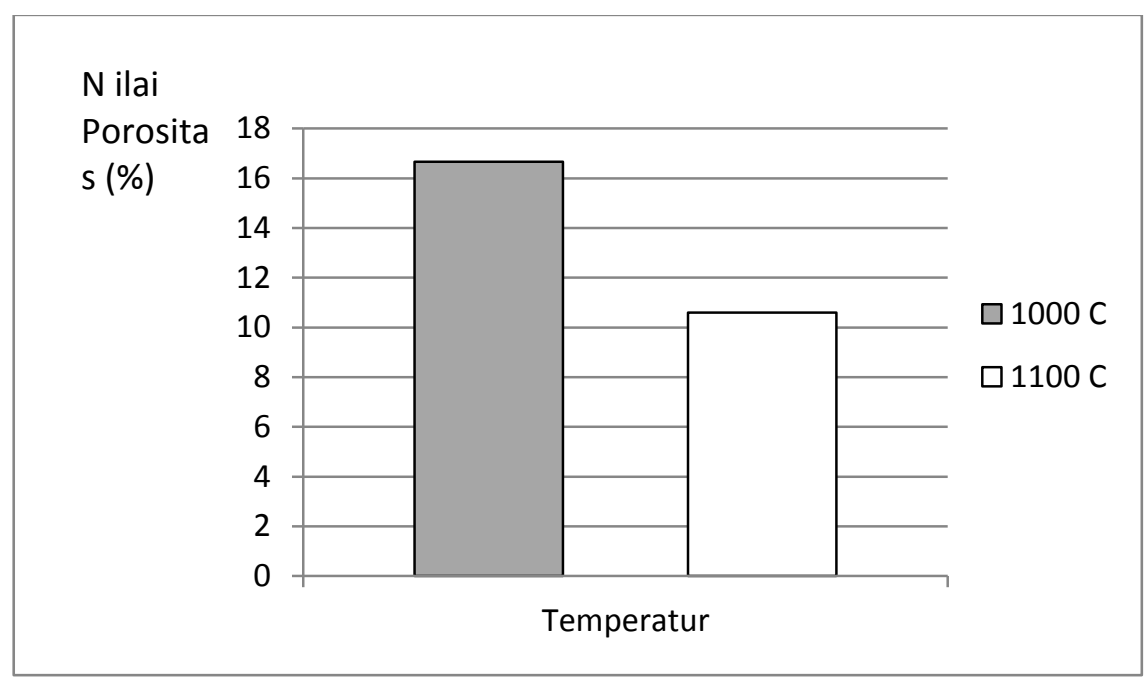

Gambar 3. Plot Temperatur Sintering dan besarnya Porositas (\%) 


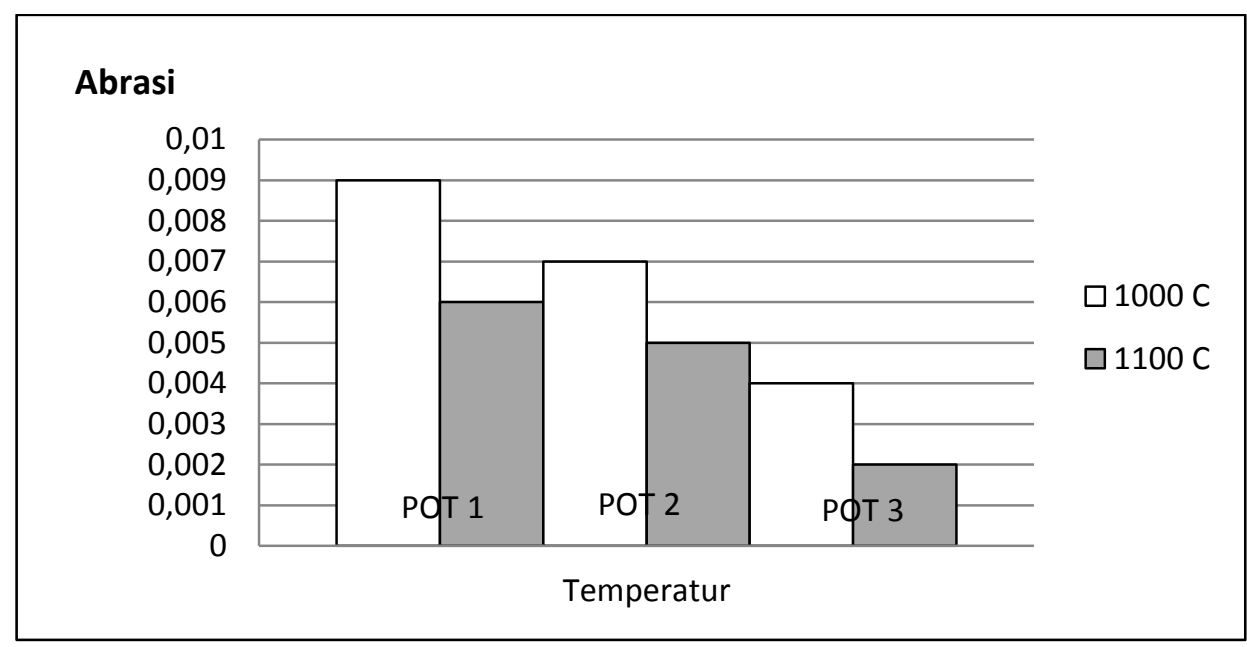

Gambar 4. Plot Temperatur Sintering dan besarnya nilai Abrasi.

\section{PENUTUP}

Ada beberapa cara untuk dapat memperpanjang umur tanur yaitu dengan memperbaiki komposisi material penyusun tanur, memakai proses sintering dan mengkombinasikan antara komposisi material dan proses sintering yang tepat. Temperatur sintering akan sangat mempengaruhi material penyusun tanur. Dimana pada temperature sintering $1100^{\circ} \mathrm{C}$ didapatkan berat jenis tanur 1,885, nilai porositas 10,59 , rata-rata nilai abrasi 0,0043 yang tentunya lebih baik jika dibanding dengan temperature sintering $1000^{\circ} \mathrm{C}$.

\section{DAFTAR PUSTAKA}

Anton J Hartomo. 1994.Mengenal Keramik Modern, edisi pertama.

Charusporn Mongkolkachit,Suda Wanakitti, Paiboon

Wattanapornphan and Sompong Srimanosaowapak. 2010. Effect of Sintering Temperature on Porous Structure of Freeze Cast Alumina.Journal of The Microscopy Society of Thailand 24 (2), 130-132

Hari Subiyanto,Subowo.2003. Pengaruh Temperatur Sintering terhadap Sifat Mekanik Keramik Insulator Listrik.Jurnal Teknik Mesin , volume 3 nomer 1 Januari .

Kingrey,1995.Intruduction to Ceramic. WD. New York. John Willey \& Son,

Mostafa Roosta, Hamidreza Baharvandi, Hossien Abdizade.2011.The Effect of Using Nano $\mathrm{ZrO}_{2}$ on The Properties of $W$-ZrC Composite Fabricated through Reaction Sintering. New Journal of Glass and Ceramics, 1,1-6.

McNamara, Edward P.1947. Ceramic,Clay Products and Whitewares.voleme 
Pensylvania.The Pensylvania State Colage.

Reed,JS.1995.Introduction to the Principles of Ceramic Processing, p.583-598.John Willey and Son.
Ramlan dan Akhmad Aminuddin Bama. 2011. Pengaruh Suhu dan Waktu Sintering terhadap Sifat Bahan Porselin untuk Bahan Elektrolit Padat (Komponen Elektroik). Jurnal Penelitian Sains, volume 14 nomer 3 (B) 14305.Juli. 